\title{
Wearable Biomechanical Energy Harvesting Technologies
}

\author{
Young-Man Choi ${ }^{\mathbb{B}}$, Moon Gu Lee and Yongho Jeon * \\ Department of Mechanical Engineering, Ajou University, Suwon 16499, Korea; ymanchoi@ajou.ac.kr (Y.-M.C.); \\ moongulee@ajou.ac.kr (M.G.L.) \\ * Correspondence: princaps@ajou.ac.kr; Tel.: +82-31-219-3652
}

Received: 12 July 2017; Accepted: 18 September 2017; Published: 25 September 2017

\begin{abstract}
Energy harvesting has been attracting attention as a technology that is capable of replacing or supplementing a battery with the development of various mobile electronics. In environments where stable electrical supply is not possible, energy harvesting technology can guarantee an increased leisure and safety for human beings. Harvesting with several watts of power is essential for directly driving or efficiently charging mobile electronic devices such as laptops or cell phones. In this study, we reviewed energy harvesting technologies that harvest biomechanical energy from human motion such as foot strike, joint motion, and upper limb motion. They are classified based on the typical principle of kinetic energy harvesting: piezoelectric, triboelectric, and electromagnetic energy harvesting. We focused on the wearing position of high-power wearable biomechanical energy harvesters (WBEHs) generating watt-level power. In addition, the features and future trends of the watt-level WBEHs are discussed.
\end{abstract}

Keywords: energy harvesting; wearable devices; human motion; electric generator; biomechanical energy

\section{Introduction}

Wearable devices that can be worn by humans in daily life or in special environments have been highlighted with the development of portable electronic devices and IoT (Internet of Things) technologies. These devices are of various types and are available in forms such as smart glasses, smart clothes, biometric sensors, artificial joints, laptops, and mobile phones. They require power ranging from several mill-watts to several tens of watts for operation. The use of wearable devices consuming high amounts of power increases the weight of batteries that are carried together and requires periodic charging. For example, in modern warfare, soldiers carry a $7 \mathrm{~kg}$-battery for $72 \mathrm{~h}$ operation of GPS devices, telecommunication equipment, and other equipment [1]. Heated clothing is used to warm the body in outdoor activities at cold temperatures, which requires a power of $\sim 10 \mathrm{~W}$ and about $1 \mathrm{~kg}$ of Lithium-ion battery for a $10 \mathrm{~h}$-usage [2]. Powered prostheses for walking consume up to $20 \mathrm{~W}$ with a $0.49 \mathrm{~kg}$-battery, which should be charged approximately every $3 \mathrm{~h}$ [3]. Such high demand of power may not be fulfilled by batteries alone. Therefore, energy harvesting devices have been studied as an assistant energy source for batteries or independent energy sources for the permanent use of wearable devices without restrictions associated with power consumption. Human energy can originate from a chemical or a physical energy source [4]. Typical sources of physical energy include the thermal and kinetic energy of the human body. Wearable thermoelectric devices $[5,6]$ convert heat from the human body into electricity of several $\mu \mathrm{W}$ continuously without affecting the human body. The human body generates kinetic energy in various forms by using muscles, such as foot strike; motions of joints such as ankle, knee, hip, arm, and elbow; and center-of-gravity (COG) motion of the upper body [7-9]. Among the human body motions, lower limb motions, such as ankle, knee, and hip motions induce 
high biomechanical energy because these joints generate a larger torque than other human joints, as listed in Table 1. In particular, during walking or gait motion, the abovementioned motions are periodically repeated, indicating that energy can be harvested continuously. The frequency of gait motion is normally about $0.5-3 \mathrm{~Hz}$ which corresponds to a walking speed of $1.3-7.8 \mathrm{~km} / \mathrm{h}$. Therefore, many studies have focused on harvesting biomechanical energy generated during gait motion.

Table 1. Biomechanical power from human motion [7-9].

\begin{tabular}{|c|c|c|c|c|}
\hline Joint/Motion & Work (J/step) & Power (W) & Max Moment (Nm) & Negative Work (\%) \\
\hline Foot strike & $1-5$ & $2-20$ & - & 50 \\
\hline Ankle & 33.4 & 66.8 & 140 & 28.3 \\
\hline Knee & 18.2 & 36.4 & 40 & 92 \\
\hline Hip & 18.96 & 38 & $40-80$ & 19 \\
\hline Elbow & 1.07 & 2.1 & 1.2 & 37 \\
\hline Center of gravity $(C O G) *$ & 10 & 20 & - & - \\
\hline
\end{tabular}

* With $20 \mathrm{~kg}$ payload [9].

Energy harvesting principles for mechanical kinetic energy include piezoelectric [10-21], triboelectric [22-31], and electromagnetic energy harvesting [1,32-48], as shown in Figure 1. Electromagnetic generators can be categorized into two types, namely inertial induction [32-39] and gear-and-generator [1,40-48]. Piezoelectric energy harvesting is based on the piezoelectric effect, in which an electric charge accumulates in certain materials in response to applied mechanical stress. Piezoelectric materials include crystals, ceramics, polymers, and proteins. Triboelectric energy harvesting is based on the triboelectric effect, in which a material become electrically charged when it comes into frictional contact with another material. Once the two materials are charged, the displacement between two can generate an electric current through an electrode connecting them. The farther the two materials are in the triboelectric series, the more charge can be obtained. Electromagnetic energy harvesting generates electricity based on Faraday's law. In inertial-induction-type energy harvesters, a permanent magnet is made to vibrate or oscillate relative to a coil using human motion. In gear-and-generator-type energy harvesters, the human motion is amplified by a gear train and the amplified motion is used to operate a rotary generator. Among these principles, inertial induction, piezoelectric, and triboelectric generators harvest relatively low amounts of power, of the order of several $\mathrm{mW}$ or lower, albeit with high power per unit volume or unit mass. Meanwhile, gear-and-generator-type energy harvesters are bulky and lead to high consumption of metabolic energy, but they can generate the highest power, up to $10 \mathrm{~W}$.

To directly drive or to assist a mobile electronic device of watt-level power consumption, an energy-harvesting device must generate watt-level electric power. Considering only generated power, the gear-and-generator-type electromagnetic energy harvester is the best candidate, and other types of energy harvesters cannot be used individually to generate high power. However, considering growing power requirements and the applications of various power ranges, combining energy harvesters based on two or more different principles is more effective than using a gear-and-generator type alone.

In this paper, we investigated wearable biomechanical energy harvesters (WBEHs) that harvest biomechanical energy from human body motion (especially from walking) and categorized them based on the working principles. This is followed by a focused review on a few representative wearable energy harvesters with watt-level output power. Finally, we discuss the features of high-power wearable energy harvesters, their applications, and future trends. 


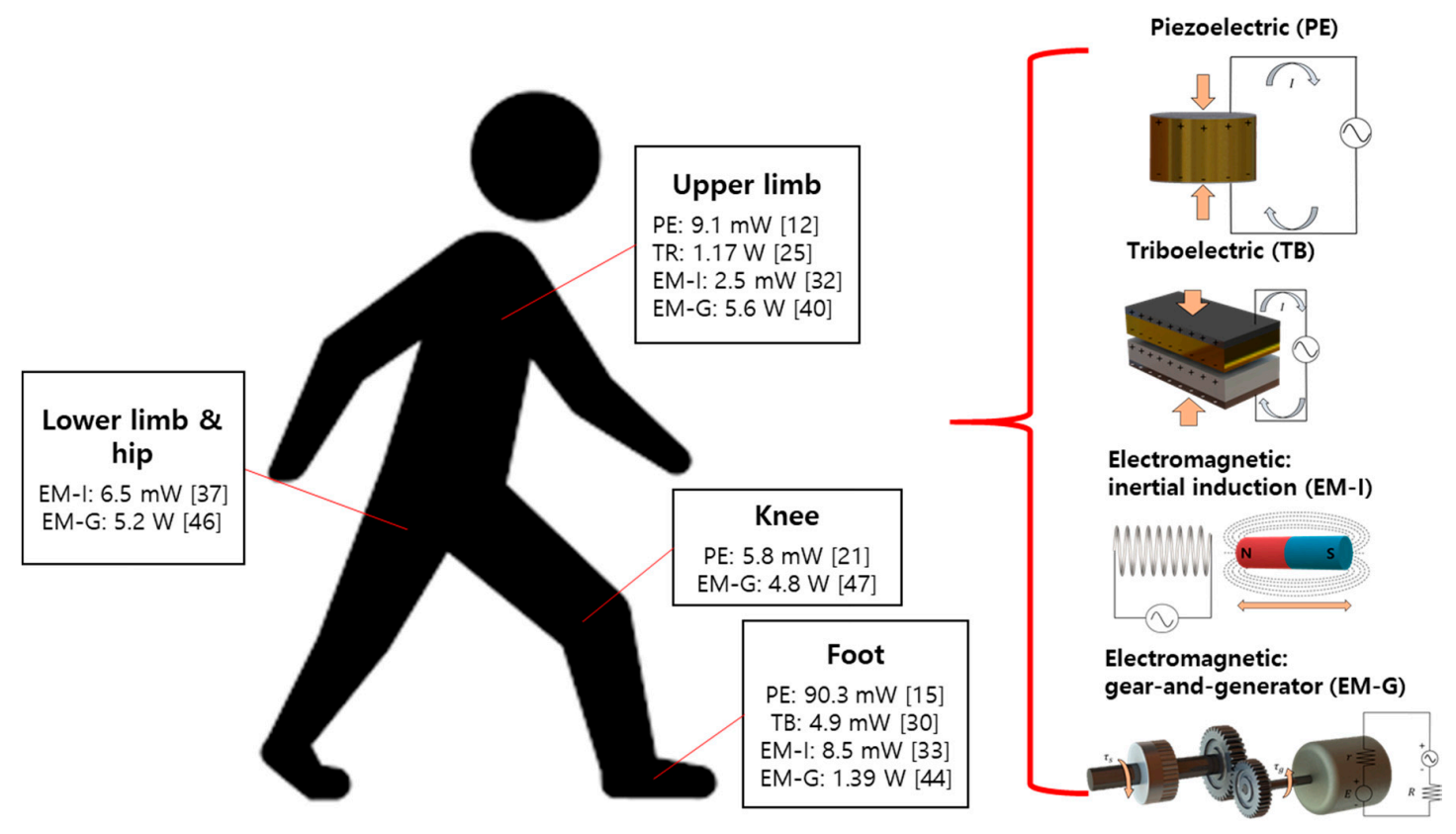

Figure 1. Electrical energy produced by human biomechanical energy sources and four typical principles of kinetic energy harvesting: piezoelectric (PE), triboelectric (TB), inertial induction type (EM-I), and gear-and-generator type (EM-G) of electromagnetic energy harvesting.

\section{Biomechanical Energy Harvesting: Principles}

This section introduces four representative principles of WBEHs and related studies. We screened these studies carefully to ensure they include actual experimental results from human motion. Thus, the sources of biomechanical energy and power outputs of WBEHs are listed and compared.

\subsection{Piezoelectric Energy Harvester (PEH)}

A piezoelectric energy harvester $(\mathrm{PEH})$ uses the piezoelectric effect to generate electricity when force is applied. A polyvinylidene fluoride (PVDF) film [12,14,16-18], lead zirconate titanate (PZT) stack [13], and PZT bimorph [15,16,19-21] have been used as piezoelectric materials for a wearable PEH. Table 2 lists recently reported wearable PEHs. Although PEHs have a low-power output, of mW-level, and poor efficiency in low-frequency regime [18], they have a small footprint in terms of volume and generates electricity even when the displacement is small. PZT is fragile and weak when subjected to shear force. However, flexible and stretchable piezoelectric devices have recently been developed and applied for harvesting energy from natural motions of internal organs [10]. In order to maximize the piezoelectric effect, it is necessary to install the $\mathrm{PEH}$ in a part of the human body that is subjected to a large compressive or tensile force. In many studies, PEHs were implemented in the shoe soles at the point where the foot applies the highest pressure in the human body [14-19]. In some cases, repetitively applied tensile force is converted into electrical energy by the COG motion of an inertial load [12,13]. Even in the absence of the direct compression/tension by the human body, vibrational energy can be converted into electrical energy by PEHs. When the piezoelectric strip is plucked mechanically or magnetically by knee motion, it vibrates and generates electric power [20,21]. 
Table 2. Wearable piezoelectric energy harvesters.

\begin{tabular}{|c|c|c|c|c|c|c|}
\hline Author, Year & Source & Material & Power $(\mathrm{mW})$ & Size $\left(\mathrm{mm}^{3}\right)$ & Weight (kg) & Reference \\
\hline Granstrom, 2007 & COG & PVDF & $9.1 \mathrm{~mW} @ 1 \mathrm{~Hz}(1)$ & $1016 \times 51 \times 0.052$ & 0.0035 & [12] \\
\hline Feenstra, 2008 & COG & PZT & $0.15 \mathrm{~mW} @ 1 \mathrm{~Hz}(2)$ & - & 0.3 & [13] \\
\hline Shenck, 2001 & Foot strike & PZT & 8.4 mW @ $1.1 \mathrm{~Hz}$ & $50 \times 50$ (insole) & - & [14] \\
\hline Howells, 2009 & Foot strike & PZT & 90.3 mW @ 1 Step & $88.9 \times 79.4 \times 42.9$ & 0.455 & [15] \\
\hline Rocha, 2010 & Foot strike & PVDF & 0.013 mW @ 1 Step & Outsole & - & [16] \\
\hline Zhao, 2014 & Foot strike & PVDF & 1 mW@ @ $1 \mathrm{~Hz}$ & $80 \times 50$ (insole) & - & [17] \\
\hline Jung, 2015 & Foot strike & PVDF & 0.5 mW@0.5 Hz & $70 \times 40 \times 0.6$ & 0.018 & [18] \\
\hline Fan, 2017 & Foot strike & PZT & $0.35 \mathrm{~mW} @ 8 \mathrm{~km} / \mathrm{h}$ & $45 \times 30 \times 24$ & 0.0223 & [19] \\
\hline Kuang, 2016 & Knee & PZT & 3.5 mW @ $0.9 \mathrm{~Hz}$ & 226000 & 0.235 & [20] \\
\hline Kuang, 2016 & Knee & PZT & $5.8 \mathrm{~mW} @ 0.9 \mathrm{~Hz}$ & - & - & [21] \\
\hline
\end{tabular}

\subsection{Triboelectric Nanogenerator (TENG)}

A triboelectric nanogenerator (TENG) is an energy harvesting device that uses triboelectrification and electrostatic induction principle. It has been attracting increasing attention since it was proposed by Wang [23] in 2012. In these devices, charges occur due to the friction between two polymers or between a polymer and a metal. Therefore, electric potential is generated owing to variations in the distance between the two materials. The efficiency of TENG depends on the triboelectric material, surface condition, contact speed, and contact area used for charging. TENGs can be configured to be light weight, flexible, and easily scalable. Generally, TENG has a high open-circuit voltage $\left(V_{O C}\right)$ of up to several hundreds of volts and peak short-circuit current $\left(I_{S C}\right)$ output for a short time, ranging from several milliseconds to several hundred milliseconds during contact or release. Thus, it is difficult to obtain a large amount of power because human body movement or human walking has a low frequency, corresponding to less than a few hertz. TENG has been reported to exhibit an instantaneous energy conversion efficiency of approximately $70 \%$ [24], but the average efficiency is reported to be only $10.6 \%$ [25] because of the output characteristics mentioned above. Moreover, reliability issues such as wear and humidity have not been resolved yet.

Table 3 lists wearable TENGs. With respect to the characteristics of TENG, the foot seems the most ideal among the human body parts, because it provides high impact velocity and conformal contact. Therefore, most extant studies on TENGs have focused on energy harvesting using foot-strike. The power output of TENGs is $\mathrm{mW}$ level, which is similar to that of PEHs. In the early stages of development, power of TENGs was not defined clearly. In such cases, we have presented the $V_{O C}$ and $I_{S C}$ values instead because the product of these two values approximates peak power. The power output of these devices can be increased by using multilayer [49] or tandem structures [50].

Table 3. Wearable triboelectric energy harvesters.

\begin{tabular}{|c|c|c|c|c|c|}
\hline Author, Year & Source & Power & Size $\left(\mathrm{mm}^{3}\right)$ & Weight (kg) & Reference \\
\hline Yang, 2013 & COG & $\begin{array}{c}V_{O C}=428 \mathrm{~V}, I_{S C}=1395 \mu \mathrm{A} \\
1.17 \mathrm{~W} \text { (peak) }\end{array}$ & - & 2 & [25] \\
\hline Hou, 2013 & Foot strike & $1.4 \mathrm{~mW}$ (peak) & $270 \times 50 \times 3$ & - & [26] \\
\hline Zhu, 2013 & Foot strike & $V_{O C}=220 \mathrm{~V}, I_{S C}=600 \mu \mathrm{A}$ & Insole & - & [27] \\
\hline Huang, 2015 & Foot strike & $2.1 \mathrm{~mW} @ 1.8 \mathrm{~Hz}$ & Insole & - & [28] \\
\hline Cheng, 2015 & Foot strike & $V_{O C}=810 \mathrm{~V}, I_{S C}=17.7 \mu \mathrm{A}$ & Insole & - & [29] \\
\hline Zhang, 2015 & Foot strike & $4.9 \mathrm{~mW}$ (peak) & $50 \times 50 \times 25$ & 0.06 & [30] \\
\hline Haque, 2016 & Foot strike & 0.25 mW @ $0.9 \mathrm{~Hz}$ (rms) & $13,300 \times 2$ & - & [31] \\
\hline
\end{tabular}

\subsection{Electromagnetic Energy Harvester: Inertial Induction Type}

Inertial induction is an energy harvesting method that involves generation of electromagnetic induction current through the relative movement of a permanent magnet or a coil. Because the power output of inertial induction is proportional to the linear velocity of magnet and coil, they are located mostly on the feet or arms, where the linear velocity is maximized in a human body. There are various 
types of inertial induction based on the arrangement of coils and magnets, as listed in Table 4. Typically, an axially magnetized permanent magnet oscillating inside a cylindrical coil along the axis of the coil is used $[32,35,37,39]$; in other cases, the permanent magnet oscillating radially at the end of the coil is used [36,38]. The oscillation evoked by human motions is maintained by using mechanical spring [36], magnetic spring [32,35,39], or both [37]. Some energy harvesters use human joint motion directly for achieving relative movement between a permanent magnet and a coil $[33,38]$. This method allows for a simple and compact energy harvester that does not significantly affect human body motion. However, the generated power is limited to a few $\mathrm{mW}$, and the low output voltage may need a complex power conversion circuit. Moreover, because it is not easy to match the mechanical resonance frequency of the device with a low frequency of human motion such as walking, which has a frequency less than $10 \mathrm{~Hz}$, maximum power conversion efficiency cannot be guaranteed.

Table 4. Wearable electromagnetic energy harvesters (inertial induction).

\begin{tabular}{|c|c|c|c|c|c|}
\hline Author, Year & Source & Power $(\mathrm{mW})$ & Size $\left(\mathrm{mm}^{3}\right)$ & Weight (kg) & Reference \\
\hline Saha, 2008 & COG & $2.5 \mathrm{~mW} @ 2.75 \mathrm{~Hz}$ & $\Phi 17 \times 55$ & - & [32] \\
\hline Duffy, 2004 & Foot & 8.5 mW@1 Hz & $\Phi 15 \times 45$ & - & [33] \\
\hline Rao, 2013 & Foot & $0.3 \mathrm{~mW} @ 4 \mathrm{~km} / \mathrm{h}$ & 100,000 & 0.217 & [34] \\
\hline Ylli, 2015 & Foot & $0.84 \mathrm{~mW} @ 6 \mathrm{~km} / \mathrm{h}$ & 21,000 & - & [35] \\
\hline Wu, 2017 & Foot & $2.3 \mathrm{~mW} @$ running & $46 \times 51 \times 10$ & - & [36] \\
\hline Morais, 2011 & Hip & $6.5 \mathrm{~mW} @ 1.85 \mathrm{~Hz}$ & 3760 & 0.0153 & [37] \\
\hline Dai, 2014 & Hip & $0.1 \mathrm{~mW} @ 5.3 \mathrm{~km} / \mathrm{h}$ & $\Phi 80 \times 10$ (except link) & 0.48 & [38] \\
\hline Geisler, 2017 & Arm & $3.94 \mathrm{~mW} @ 6.4 \mathrm{~km} / \mathrm{h}$ & 9000 & 0.02 & [39] \\
\hline
\end{tabular}

\subsection{Electromagnetic Energy Harvester: Gear-and-Generator Type}

The method of operating a rotary electric generator is a classical power generation technique. Devices based on this technique generate significantly higher power than those based on other techniques. As can be inferred from Table 5, with such devices, it is possible to harvest energy by using the center-of-gravity movement of the upper body, the foot-strike, lower limb movement, and knee joint motion is possible, and watt-level power can be generated at normal walking speed [1,40-48]. To develop an appropriate voltage of approximately 5-24 V from a portable rotary generator, it is necessary to achieve a rotation speed of 3000-6000 rpm by amplifying the speed of the human body motion using the gear train. Linear motion of inertial mass, such as foot-strike and COG movement, is converted into a rotational motion of the generator by a rack gear. Rotational motion such as knee joint motion, is amplified using a multi-stage gear train to match the rated speed of the generator, thus optimizing power conversion efficiency. In the case of gear and rotary generators, reaction torque [51] developed at the time of power generation is transmitted to the human body, leading to consumption of a corresponding amount of metabolic energy.

Table 5. Wearable electromagnetic energy harvesters (gear-and-generator).

\begin{tabular}{|c|c|c|c|c|c|c|}
\hline Author, Year & Source & Power (W) & $\begin{array}{l}\text { Size }\left(\mathrm{mm}^{3}\right) \text { or } \\
\text { Shape }\end{array}$ & Weight (kg) & $\begin{array}{c}\text { Efficiency } \\
(\%)\end{array}$ & Reference \\
\hline Rome, 2005 & COG & $5.6 \mathrm{~W} @ 5.6 \mathrm{~km} / \mathrm{h}$ & Backpack & 38 & $30-40$ & [40] \\
\hline Xie, 2015 & COG & $4.1 \mathrm{~W} @ 5.6$ km/h & Backpack & 15 & - & [41] \\
\hline Yuan, 2017 & $\mathrm{COG}$ & $4.8 \mathrm{~W} @ 5.6 \mathrm{~km} / \mathrm{h}$ & Backpack & 15 & - & [1] \\
\hline Hayashida, 2000 & Foot & $0.059 \mathrm{~W} @ 1 \mathrm{~Hz}$ & Outsole & - & - & [42] \\
\hline Purwadi, 2015 & Foot & $1.1 \mathrm{~W} @ 7.2$ km/h & $59 \times 31 \times 25$ & 0.5 & $26.7-42.9$ & [43] \\
\hline Xie, 2015 & Foot & 1.39 W @ 5 km/h & $80 \times 47 \times 22$ & 0.137 & 57 & [44] \\
\hline Xie, 2016 & Foot & $0.35 \mathrm{~W} @ 7.2 \mathrm{~km} / \mathrm{h}$ & $98 \times 70 \times 20$ & 0.126 & 51 & [45] \\
\hline Shepertycky, 2015 & Lower limb & 5.2 W @ 5.6 km/h & - & 2.66 & 70 & [46] \\
\hline Donelan, 2008 & Knee & $4.8 \mathrm{~W} @ 5.4$ km/h & Knee brace & 1.6 & 56 & [47] \\
\hline Chen, 2017 & Knee & $3.6 \mathrm{~W} @ 5.4$ km/h & $145 \times 66 \times 67$ & 0.44 & - & [48] \\
\hline
\end{tabular}

Despite their large reaction torque and bulky structure, gear-and-generator-type energy harvesters have become meaningful in biomechanical energy harvesting owing to the emergence of research on 
using negative work [8] in human gait motion. Negative work refers to metabolic energy consumed by joints during a decelerating motion. The mechanical energy conversion efficiency of metabolic energy during gait motion exceeds that of all of the other body motions because negative work is stored in and reused by the muscles [52]. Niu et al. [7] proposed that if a generator that absorbs negative work is placed on the knee, it is possible to harvest electrical energy and simultaneously reduce the burden on the muscles. Donelan et al. [47] implemented the above idea in the form of a knee generator. The details of the knee generator will be explained in Section 3.4.

\subsection{Device Efficiency}

Table 6 presents the device efficiencies of several wearable energy harvesters. Device efficiency refers to the ratio of harvested electrical energy to input mechanical energy. The device efficiencies of conventional energy harvesters are $10-70 \%$. The device efficiency of a gear-and-generator-type electromagnetic energy harvesters is relatively higher than those of other types of energy harvesters. Because PEHs have the highest efficiency at natural frequencies of the order of $\mathrm{kHz}$ [53], their efficiency is low in low-frequency regimes such as human motion. Moreover, the impulsive output of triboelectric energy harvesters leads to a low device efficiency when averaged at low frequencies. Thus, electromagnetic energy harvesters seem to be the best candidate for high-power WBEH owing to their high power output and high device efficiency.

In addition to device efficiency, circuit efficiency of the power conversion circuit used in such devices affects overall efficiency in terms of producing a usable DC output for use in electronics or batteries [54]. A power conversion circuit typically includes a rectifier, AC-DC converter, and voltage conditioning circuit $[55,56]$. To maximize circuit efficiency, the circuit impedance should be matched with that of the energy harvesting device. The details of the power conversion circuit are beyond the scope of this paper.

Table 6. Device efficiency of wearable energy harvesters.

\begin{tabular}{ccccc}
\hline Type & Piezoelectric & Triboelectric & $\begin{array}{c}\text { Electromagnetic } \\
\text { (Inertial Induction) }\end{array}$ & $\begin{array}{c}\text { Electromagnetic } \\
\text { (Gear-and-Generator) }\end{array}$ \\
\hline $\begin{array}{c}\text { Device } \\
\text { efficiency (\%) }\end{array}$ & $12-16[20], 10[57]$ & $10.6[25]$ & $45[39]$ & $30-40[40], 26.7[43]$, \\
\hline
\end{tabular}

\section{Review of High-Power Wearable Biomechanical Energy Harvesters}

As described in Section 2, watt-level power output of gear-and-generator is unique among WBEHs. This section describes the features of gear-and-generator-type WBEHs based on source of human mechanical motion.

\subsection{Figure-of-Merit for Wearable Biomechanical Energy Harvesting}

In WBEHs, device efficiency cannot represent the interaction between the device and human muscles. During human motion, muscles perform negative work that a WBEH can replace, thus, simultaneously reducing metabolic energy consumed by muscles. To quantify muscle effort required for generating electrical power, two figures-of-merit have been proposed. First, cost of harvesting $(\mathrm{COH})$ is proposed in [44]. $\mathrm{COH}$ is defined as the additional metabolic power in watts required to generate $1 \mathrm{~W}$ of electrical power compared to the metabolic power for a harvester in the disengaged mode. In the disengaged mode, transmission or gear is disengaged manually so that it is never in motion [51]. $\mathrm{COH}$ of conventional energy harvesters, which do not use negative work, can be expressed as follows [47]:

$$
\mathrm{COH}=\frac{1}{(\text { EH device efficiency) (muscle efficiency) }}
$$


Given that the efficiency of human muscle is approximately $25 \%$, which is similar to that of an internal combustion engine [58] and the maximum device efficiency of a conventional energy harvester is approximately $70 \%$, the lowest possible $\mathrm{COH}$ of conventional energy harvesters is 5.7 . The $\mathrm{COH}$ of WBEHs using negative work, is expressed as follows [44]:

$$
\mathrm{COH}=\frac{\text { Metabolic power with EH on }- \text { Metabolic power with EH off }}{\text { electrical power }}
$$

If a WBEH harvests negative work of muscles, thus reducing metabolic power consumed by them, muscle efficiency can be increased up to $120 \%$ [46] and even $\mathrm{COH}$ can be reduced to be less than 1 [47]. However, $\mathrm{COH}$ does not consider metabolic energy required for carrying the weight of the energy harvester itself. Thus, $\mathrm{TCOH}$ (total cost of harvesting) is proposed for a fundamental comparison with the absence of a harvester [46], and it is expressed as follows:

$$
\mathrm{TCOH}=\frac{\text { Metabolic power with EH on }- \text { Metabolic power without EH }}{\text { electrical power }}
$$

$\mathrm{TCOH}$ means total metabolic power required for carrying and activating the $\mathrm{WBEH}$, and it is a better metric for quantifying the user's overall effort in harvesting electrical energy [46]. To ensure $\mathrm{TCOH}$ is low, the energy harvester should be light weight and be located near the human COG.

\subsection{COG Motion}

The COG of the upper body moves up and down while walking. To effectively convert this COG movement into electrical energy, several researchers implemented energy harvesters in the form of a backpack. The backpack energy harvester developed by Rome et al. [40] in 2005, as shown in Figure 2, is a pioneering work. This energy harvester converts COG motion of a moving load into rotational motion of a generator through a rack gear and pinion system. Bushings constrained to vertical rods are used to move the load up and down freely, and a spring is used to restore movement of the moving load. The backpack energy harvester outputs $5.6 \mathrm{~W}$ when worn by a person walking at $5.6 \mathrm{~km} / \mathrm{h}$ with $38 \mathrm{~kg}$ of moving mass. However, this harvester has a high TCOH value [46] because of its large moving mass; thus, it is effective when a large load is originally required. Xie et al. [41] further optimized the backpack energy-harvesting mechanism. For a higher power generation, two pairs of a rack gear and generator were used. They achieved a power of $4.1 \mathrm{~W}$ with a $15 \mathrm{~kg}$ moving mass at the same walking speed as that in [40].

The direct connection between the rack gear and generator in the aforementioned energy harvesters results in several problems: The gears and generator shaft experience reverse stress, which shortens their fatigue lifetime. Moreover, because the rotation direction keeps changing, the resulting rotational inertia of the generator reduces energy conversion efficiency. Moreover, because alternating current is generated, a rectifying circuit must be used to produce a direct-current, and this inevitably causes power loss. Yuan [1] has recently proposed a backpack energy harvester, as shown in Figure 3, using a mechanical motion rectifier (MMR) to solve the above problems. The MMR uses a rack gear and one-way bearing to convert bi-directional body movements to unidirectional rotation of the generator. Thus, under the same conditions as those in [41], this device exhibits an increased output of $4.8 \mathrm{~W}$. 




Figure 2. Backpack energy harvester: The pack frame is fixed to the body, but the load, mounted on the load plate, is suspended by springs (red) from the frame (blue): (A) During walking, the load is free to ride up and down on bushings along vertical rods; (B) [40]. Reproduced with permission from the American Association for the Advancement of Science.



Figure 3. Backpack energy harvester using a mechanical motion rectifier (MMR) [1]. A power-take-off unit (PTO) consists of a MMR and a generator. The MMR uses a rack gear and a one-way bearing to convert bi-directional body movements to a unidirectional rotation of the generator. One end of the rack gear is fixed to the human body and the PTO moves up and down with the moving board supported by springs. Reproduced with permission from the Society of Photo Optical Instrumentation Engineers (SPIE). 


\subsection{Foot-Strike}

A foot-strike WBEH uses the impact or pressure generated by the foot while walking. Hayashida [14,42] implemented an energy harvester in the heel of a shoe using a gear train, belts, and two generators, as shown in Figure 4. The lever protruding from the outsole of a shoe is rotated each time a footstep is taken, and the end of the lever is connected to the gear train driving the generator by belts. With this device, it is possible to generate power for about $10 \%$ of the time spent walking. A low output of $59 \mathrm{~mW}$ is obtained owing to the short duration of power generation and low mechanical efficiency of the belt. Purwadi et al. [43] implemented a foot-strike energy harvester using gears and a generator without belts to achieve an increased output of $110 \mathrm{~mW}$ while walking.



Figure 4. Foot-strike wearable energy harvester implemented in an outsole using a three-stage gear train and generator [14]. When the foot strikes the ground, a lever rotates the gear train transmitting the rotational motion to the generators via belts. Reproduced with permission from the IEEE.

Figure 5 shows a new energy harvester proposed by Xie [44]. This device is mounted on a shoe heel, and it amplifies foot-strike motion using a trapezoidal sliding mechanism and transmits the amplified motion to a generator through a rack and gear train. Four vertical springs and two horizontal springs are employed to provide a restoring force for the trapezoidal slider mechanism, and this configuration allows the harvester to generate electricity during the return motion. This harvester achieved the highest output of $1.39 \mathrm{~W}$ among foot-strike energy harvesters.

Instead of direct foot-strike motion, inertial impact and vibration caused by foot strike can be utilized for energy harvesting. Recently, Xie [42] has developed a miniaturized energy harvester, presented in Figure 6, based on the same principle as that proposed in [40] and installed on the ankle. Using the inertial vibration generated by foot-strikes, it achieves an output of $0.35 \mathrm{~W}$ at a fast walking speed of $7.2 \mathrm{~km} / \mathrm{h}$. 


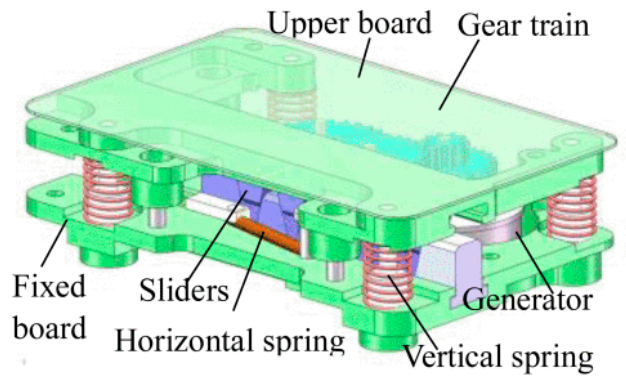

(a)

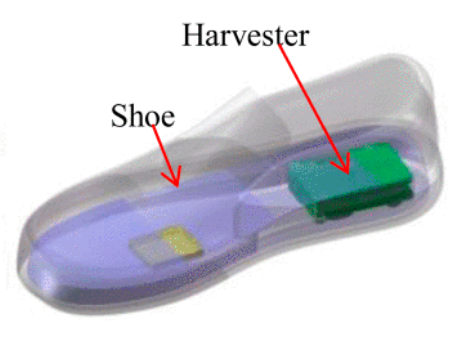

(b)

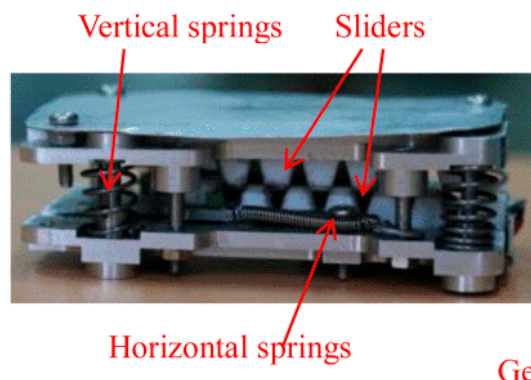

(c)
Generator Gear train Guiding track

(d)

Figure 5. Foot-strike wearable energy harvester using a trapezoidal motion amplifier [44]: (a) 3-D model of in-shoe energy harvester; (b) harvester assembled in the heel area of a shoe; (c) front view; and (d) overview of the harvester prototype. Reproduced with permission from the IEEE.
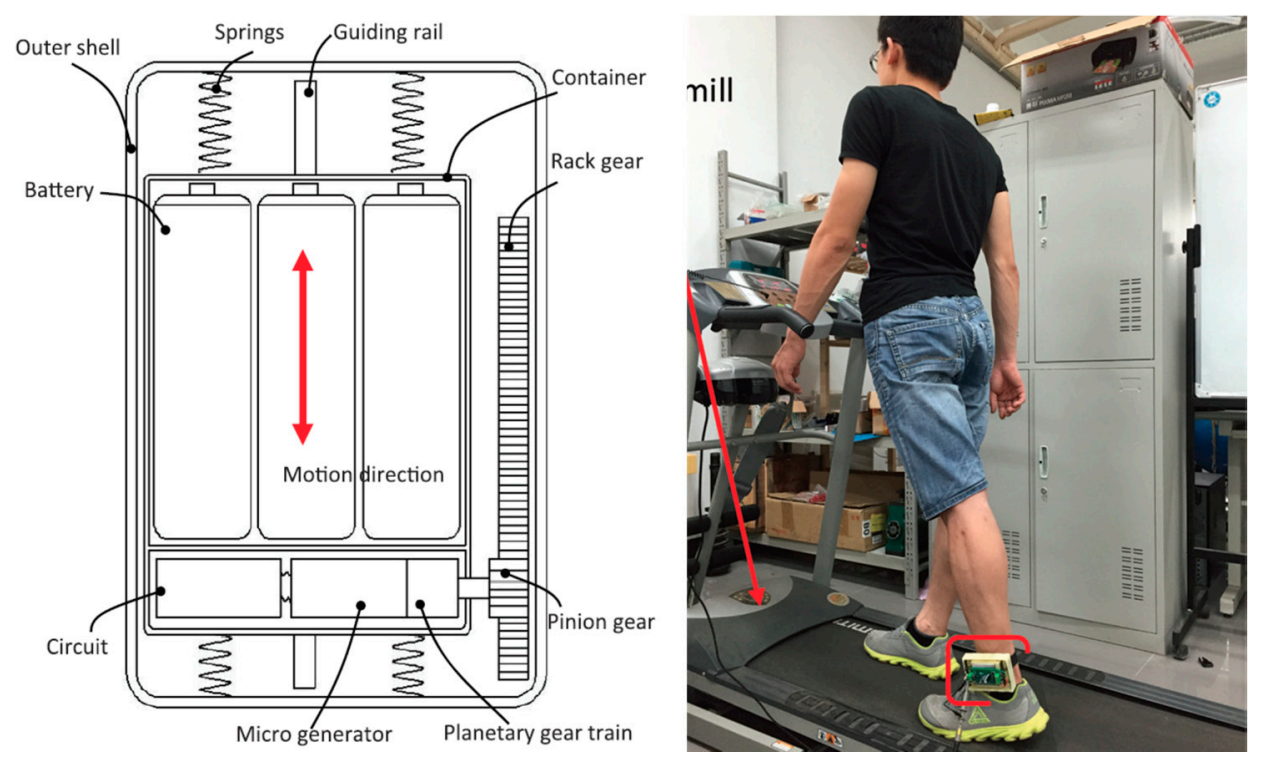

Figure 6. Foot-strike wearable energy harvester using inertial motion [45]: Schematic of the energy harvester (left) and energy harvester mounted on the ankle (right). Reproduced under a Creative Commons Attribution CC-BY 3.0 license.

\subsection{Lower Limb (Leg Motion)}

In gait motion, the lower body repeats motion relative to the upper body. As shown in Figure 7, Shepertycky et al. [46] proposed an energy harvester in which a cable connects the hip and the ankle, and electricity is generated using linear displacement of the cable due to walking. The harvester was placed directly under the waist because its position significantly affects biomechanical energy required 
to shift the weight of the harvester. The cable was wound on a pulley to generate rotational motion and to transmit the generated rotation to the gear connected to the roller clutch. The roller clutch transferred rotation only to the gear when the cable was stretched, and it did not transmit rotation when the cable contracted. This mechanism has the same effect as generative braking [47], which is explained in Section 3.5, because it helps knee flexor muscles to slow down the knee in the latter half of the swing phase of the leg. The energy harvester generates $5.6 \mathrm{~W}$ at a walking speed of $5.6 \mathrm{~km} / \mathrm{h}$. Finally, a TCOH of 4.0 is obtained (i.e., total metabolic energy consumed to generate $1 \mathrm{~W}$ of electrical energy corresponds to $4 \mathrm{~W}$ ).

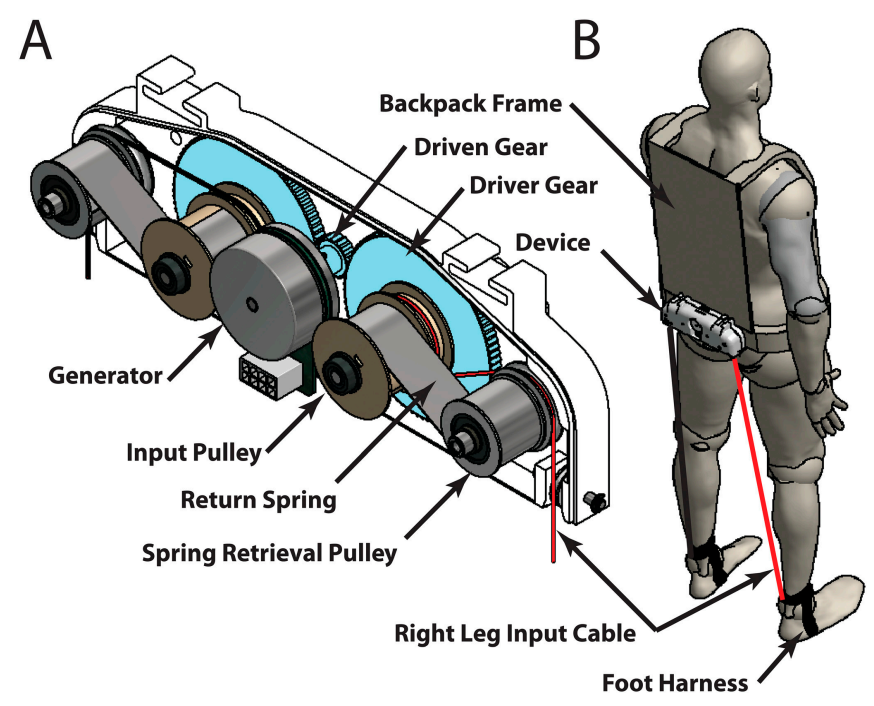

Figure 7. Lower-limb driven wearable energy harvesters [46]: (A) schematic of device components; (B) schematic view of the device worn by the user. Reproduced under a Creative Commons Attribution CC-BY 4.0 license.

\subsection{Knee Motion}

Theoretically, a knee joint allows for harvesting of the most amount of energy among the joints in the human body. In 2008, Donelan et al. [47] proposed a gear-and-generator-type wearable energy harvester that converts rotational motion of the knee joint into electrical energy, as shown in Figure 8. This energy harvester is equipped with a three-stage gear train that converts low velocity and high torque at the knee into high velocity and low torque for the generator, by means of a one-way roller clutch that allows for the selective engagement of the gear train during knee extension and no engagement during knee flexion [47]. When the gear train is engaged, the generator generates a current through the electric load. At the same time, generator torque is generated from the current, which is amplified by the gear train and finally presented as reaction torque to knee muscles. A computer-controlled feedback system determines when to generate power using knee-angle feedback and relay switch, and the knee angle is measured with a potentiometer mounted on the input shaft [47].

The knee energy harvester generates an electricity base on a technology called generative braking, which is analogous to regenerative braking in hybrid cars. Figure 9 explains generative braking with the positive and negative work during gait motion. The generator generates the electricity only during the negative work phase, providing reaction torque to the knee, and this torque helps the muscle to decelerate the knee joint while reducing negative work. Thus, generative braking reduces the consumption of metabolic energy and leads to higher efficiency as compared to continuous generation. For this purpose, a one-way roller clutch is used to engage the generator with the gear train only in the latter half of the swing phase. Furthermore, the on-off state of the relay switch is controlled based on knee-angle feedback to maximize generator output. Consequently, the device produces $4.8 \mathrm{~W}$ of 
power while walking at $5.6 \mathrm{~km} / \mathrm{h}$. In this case, $\mathrm{COH}$ is less than 1 , which means that less than $1 \mathrm{~W}$ of additional metabolic energy is consumed for $1 \mathrm{~W}$ of harvested electrical energy.
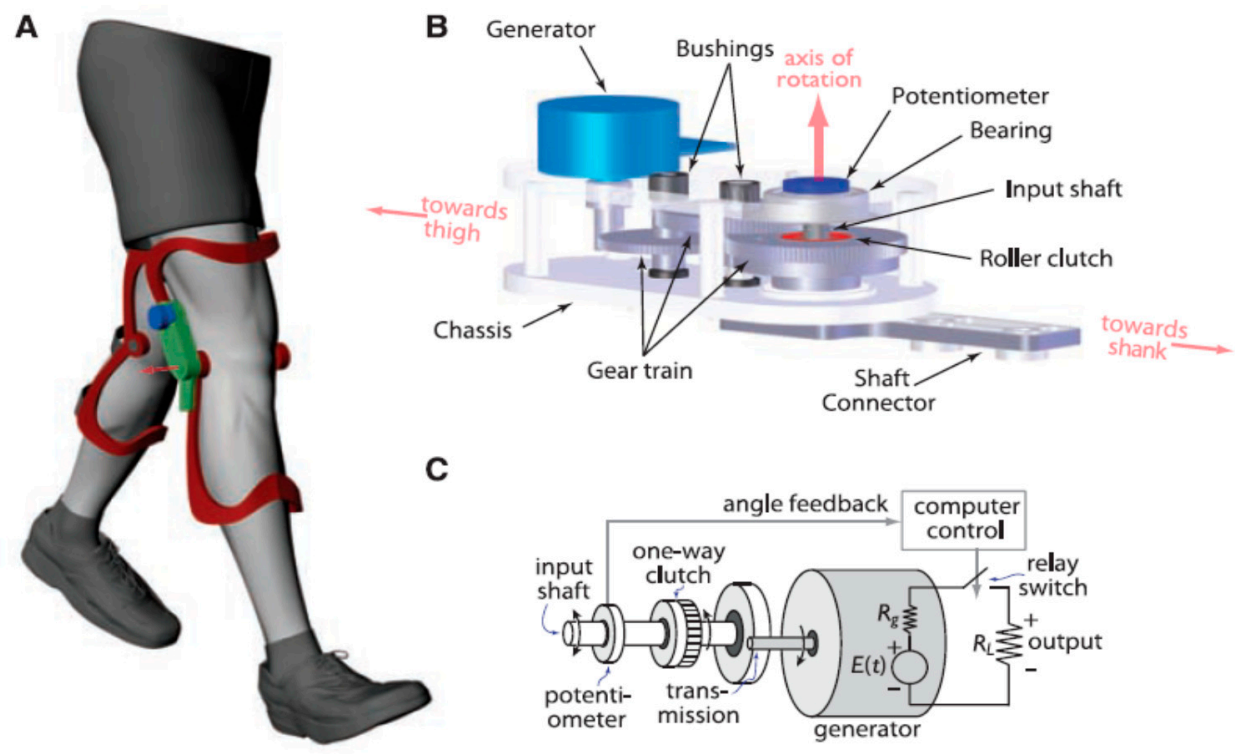

Figure 8. Knee wearable energy harvester with generative braking: (A) Conceptual drawing of the knee energy harvester; (B) its configuration of the knee energy harvester; and (C) schematic diagram of computer-controlled feedback system [47]. Reproduced with permission from the American Association for the Advancement of Science.

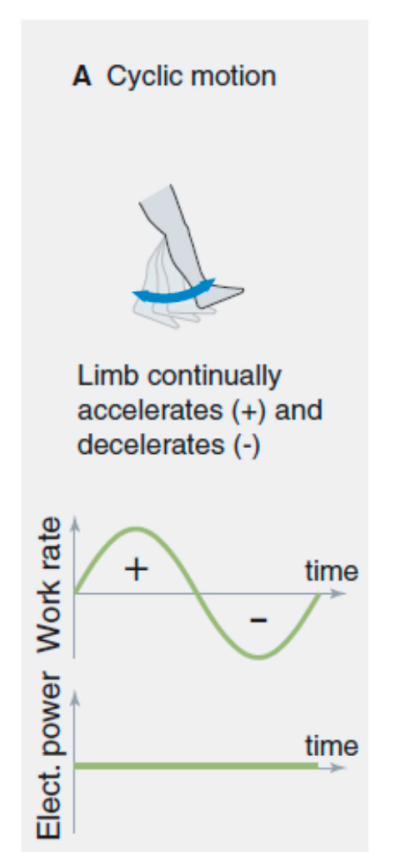

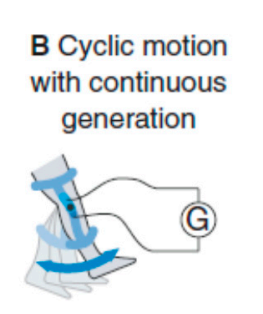

Generator $(G)$ resists acceleration, assists deceleration

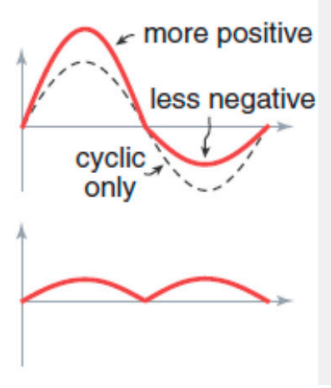

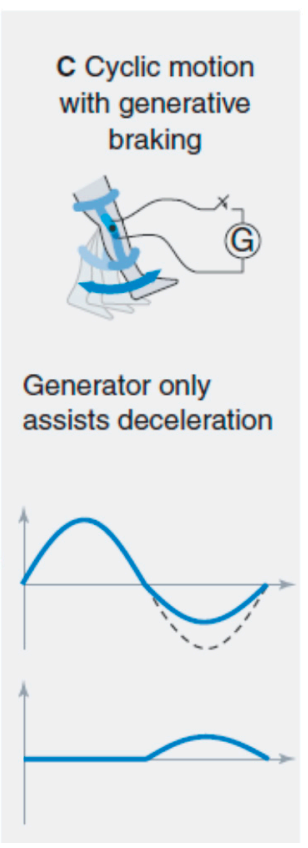

Figure 9. Generative braking [47]. Harvesting energy from negative work: (A) cyclic motion of limb without an energy harvester, (B) with continuous generation, and (C) with generative braking. Reproduced with permission from the American Association for the Advancement of Science.

Chen et al. [48] also developed a knee energy harvester, as shown in Figure 10. To solve the rectifying issue described in Section 3.2, they installed one-way bearings and gear sets in two opposite directions to transfer the reciprocating rotational motion of the legs unidirectionally to the generator. 
With this device, they generate $3.6 \mathrm{~W}$ using continuous energy harvesting method. Additionally, the weight of the entire device was reduced by $30 \%$, compared with that in [47], by using a plastic shell.


Figure 10. Knee wearable energy harvester with unidirectional generator rotation [48]. Reproduced with permission from IOP Publishing.

Recently, a company have commenced work to commercialize the knee harvester shown in Figure 11. PowerWalk ${ }^{\circledR}$ is being developed to have a power output of $10 \mathrm{~W}$ while walking at $5 \mathrm{~km} / \mathrm{h}$ on a flat ground; the target device weight is $900 \mathrm{~g}$ per leg [59].

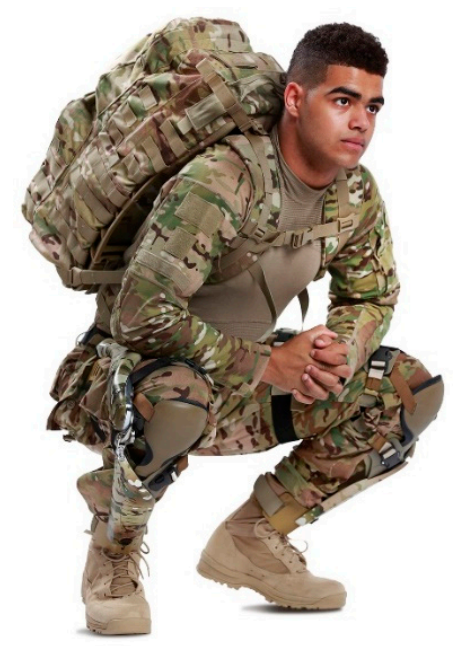

Figure 11. PowerWalk ${ }^{\circledR}$ knee energy harvester [59].

\section{Concluding Remarks and Future Perspectives}

In this paper, we reviewed WBEHs, which harvest human kinetic energy. We categorized these devices based on their energy harvesting principles as follows: triboelectric, piezoelectric, and electromagnetic energy harvesting. We focused on high-power energy harvesters. For various human motions, the design, mechanism, and performances of the representative high-power energy harvesters were explained. Human gait motion was of interest in this review because it simultaneously provides high power and high efficiency. For watt-level power energy harvesting, a gear-and-generator-type electromagnetic energy harvesters were found to be practical.

In the future, WBEHs will be developed along two major directions. The first is low-power and low-burden energy harvesters to supply power to wearable devices such as implantable power sources in humans/animals [22]. Such devices should be light weight, and their consumption 
of metabolic energy should be negligible to ensure the wearer does not feel discomfort. Flexible and stretchable devices would be suitable for these applications [10]. Thermoelectric, triboelectric, piezoelectric, and inertial induction methods will be used, and the outputs will ranges from several $\mu \mathrm{W}$ to several $\mathrm{mW}$. Miniaturization of power conversion circuits and battery systems could be of interest. The second direction is high-power WBEHs for charging mobile electronic devices such as laptops, cell phones, and radios. The gear-and-generator method is a promising solution to generate more than $10 \mathrm{~W}$. The resulting high-power WBEHs would be essential for military or leisure purposes from the viewpoint of enhancing safety, efficiency, and survival [59]. In addition to high power, it is essential to ensure low metabolic energy consumption $(\mathrm{COH}, \mathrm{TCOH})$. To improve power output and efficiency of WBEHs, their mechanical design should be optimized, for example, by developing gear trains with small form factors and low friction, and though precise alignment of shafts and bearings [60]. Such WBEHs must be sufficiently light weight to reduce metabolic energy consumed in carrying them. To this end, the weight of bearings, gears, and frames, which are essential mechanical elements of these devices, should be reduced [50]. New materials such carbon fibers, ceramics, and composite polymers could be considered as materials for chassis, gears, and bearings. Generative braking or the use of negative work can be expanded to other human motions such as those of the ankle or hip. Finally, combinations of different types of WBEHs can be used viably for stable power generation under various circumstances.

Acknowledgments: This study was supported by the New Faculty Research Fund of Ajou University.

Author Contributions: Young-Man Choi, Moon Gu Lee and Yongho Jeon wrote the paper

Conflicts of Interest: The authors have no conflicts of interest to declare.

\section{References}

1. Yuan, Y.; Liu, M.; Tai, W.-C.; Zuo, L. Design and experimental studies of an energy harvesting backpack with mechanical motion rectification. In Proceedings of the SPIE Smart Structures and Materials + Nondestructive Evaluation and Health Monitoring, Portland, OR, USA, 12 April 2017.

2. Wang, F.; Gao, C.; Kuklane, K.; Holmer, I. A review of technology of personal heating garments. Int. J. Occup. Saf. Ergon. 2010, 16, 387-404. [CrossRef] [PubMed]

3. Power Knee ${ }^{\mathrm{TM}}$. Available online: https://www.ossur.com/prosthetic-solutions/products/dynamicsolutions/power-knee (accessed on 20 September 2017).

4. Sue, C.Y.; Tsai, N.C. Human powered MEMS-based energy harvest devices. Appl. Energy 2012, 93, 390-403. [CrossRef]

5. Kishi, M.; Nemoto, H.; Hamao, T.; Yamamoto, M.; Sudou, S.; Mandai, M.; Yamamoto, S. Micro thermoelectric modules and their application to wristwatches as an energy source. In Proceedings of the Eighteenth International Conference on Thermoelectrics, Baltimore, MD, USA, 29 August-2 September 1999; pp. 301-307. [CrossRef]

6. Kim, S.J.; We, J.H.; Cho, B.J. A wearable thermoelectric generator fabricated on a glass fabric. Energy Environ. Sci. 2014, 7, 1959. [CrossRef]

7. Niu, P.; Chapman, P.; Riemer, R.; Zhang, X. Evaluation of motions and actuation methods for biomechanical energy harvesting. In Proceedings of the 2004 IEEE 35th Annual Power Electronics Specialists Conference (IEEE Cat. No. 04CH37551), Aachen, Germany, 20-25 June 2004; Volume 3, pp. 2100-2106. [CrossRef]

8. Winter, D.A. Biomechanics and Motor Control of Human Movement, 4th ed.; John Wiley \& Sons: Hoboken, NJ, USA, 2009; ISBN 9780470398180.

9. Riemer, R.; Shapiro, A. Biomechanical energy harvesting from human motion: Theory, state of the art, design guidelines, and future directions. J. Neuroeng. Rehabil. 2011, 8, 22. [CrossRef] [PubMed]

10. Dagdeviren, C.; Joe, P.; Tuzman, O.L.; Park, K.-I.; Lee, K.J.; Shi, Y.; Huang, Y.; Rogers, J.A. Recent progress in flexible and stretchable piezoelectric devices for mechanical energy harvesting, sensing and actuation. Extrem. Mech. Lett. 2016, 9, 269-281. [CrossRef] 
11. Persano, L.; Dagdeviren, C.; Su, Y.; Zhang, Y.; Girardo, S.; Pisignano, D.; Huang, Y.; Rogers, J.A. High performance piezoelectric devices based on aligned arrays of nanofibers of poly(vinylidenefluorideco-trifluoroethylene). Nat. Commun. 2013, 4, 1633. [CrossRef] [PubMed]

12. Granstrom, J.; Feenstra, J.; Sodano, H.A.; Farinholt, K. Energy harvesting from a backpack instrumented with piezoelectric shoulder straps. Smart Mater. Struct. 2007, 16, 1810-1820. [CrossRef]

13. Feenstra, J.; Granstrom, J.; Sodano, H. Energy harvesting through a backpack employing a mechanically amplified piezoelectric stack. Mech. Syst. Signal Process. 2008, 22, 721-734. [CrossRef]

14. Shenck, N.S.; Paradiso, J.A. Energy scavenging with shoe-mounted piezoelectrics. IEEE Micro 2001, $21,30-42$. [CrossRef]

15. Howells, C.A. Piezoelectric energy harvesting. Energy Convers. Manag. 2009, 50, 1847-1850. [CrossRef]

16. Rocha, J.G.; Goncalves, L.M.; Rocha, P.F.; Silva, M.P.; Lanceros-Mendez, S. Energy harvesting from piezoelectric materials fully integrated in footwear. IEEE Trans. Ind. Electron. 2010, 57, 813-819. [CrossRef]

17. Zhao, J.; You, Z. A Shoe-embedded piezoelectric energy harvester for wearable sensors. Sensors 2014, 14, 12497-12510. [CrossRef] [PubMed]

18. Jung, W.S.; Lee, M.J.; Kang, M.G.; Moon, H.G.; Yoon, S.J.; Baek, S.H.; Kang, C.Y. Powerful curved piezoelectric generator for wearable applications. Nano Energy 2015, 13, 174-181. [CrossRef]

19. Fan, K.; Liu, Z.; Liu, H.; Wang, L.; Zhu, Y.; Yu, B. Scavenging energy from human walking through a shoe-mounted piezoelectric harvester. Appl. Phys. Lett. 2017, 110, 143902. [CrossRef]

20. Kuang, Y.; Zhu, M. Characterisation of a knee-joint energy harvester powering a wireless communication sensing node. Smart Mater. Struct. 2016, 25, 55013. [CrossRef]

21. Kuang, Y.; Yang, Z.; Zhu, M. Design and characterisation of a piezoelectric knee-joint energy harvester with frequency up-conversion through magnetic plucking. Smart Mater. Struct. 2016, 25, 85029. [CrossRef]

22. Dagdeviren, C.; Li, Z.; Wang, Z.L. Energy harvesting from the animal/human body for self-powered electronics. Annu. Rev. Biomed. Eng. 2017, 19, 85-108. [CrossRef] [PubMed]

23. Fan, F.R.; Tian, Z.Q.; Wang, Z.L. Flexible triboelectric generator. Nano Energy 2012, 1, 328-334. [CrossRef]

24. Wang, Z.L.; Lin, L.; Chen, J.; Niu, S.; Zi, Y. Triboelectric Nanogenerators; Springer: Cham, Switzerland, 2016; ISBN 978-3-319-40038-9.

25. Yang, W.; Chen, J.; Zhu, G.; Yang, J.; Bai, P.; Su, Y.; Jing, Q.; Cao, X.; Wang, Z.L. Harvesting energy from the natural vibration of human walking. ACS Nano 2013, 7, 11317-11324. [CrossRef] [PubMed]

26. Hou, T.C.; Yang, Y.; Zhang, H.; Chen, J.; Chen, L.J.; Lin Wang, Z. Triboelectric nanogenerator built inside shoe insole for harvesting walking energy. Nano Energy 2013, 2, 856-862. [CrossRef]

27. Zhu, G.; Bai, P.; Chen, J.; Wang, Z.L. Power-generating shoe insole based on triboelectric nanogenerators for self-powered consumer electronics. Nano Energy 2013, 2, 688-692. [CrossRef]

28. Huang, T.; Wang, C.; Yu, H.; Wang, H.; Zhang, Q.; Zhu, M. Human walking-driven wearable all-fiber triboelectric nanogenerator containing electrospun polyvinylidene fluoride piezoelectric nanofibers. Nano Energy 2015, 14, 226-235. [CrossRef]

29. Cheng, X.; Meng, B.; Zhang, X.; Han, M.; Su, Z.; Zhang, H. Wearable electrode-free triboelectric generator for harvesting biomechanical energy. Nano Energy 2015, 12, 19-25. [CrossRef]

30. Zhang, K.; Wang, X.; Yang, Y.; Wang, Z.L. Hybridized electromagnetic-triboelectric nanogenerator for scavenging biomechanical energy for sustainably powering wearable electronics. ACS Nano 2015, 9, 3521-3529. [CrossRef] [PubMed]

31. Haque, R.I.; Farine, P.-A.; Briand, D. Fully casted soft power generating triboelectric shoe insole. J. Phys. Conf. Ser. 2016, 773, 12097. [CrossRef]

32. Saha, C.R.; O'Donnell, T.; Wang, N.; McCloskey, P. Electromagnetic generator for harvesting energy from human motion. Sens. Actuators A Phys. 2008, 147, 248-253. [CrossRef]

33. Duffy, M.; Carroll, D. Electromagnetic generators for power harvesting. In Proceedings of the 2004 IEEE 35th Annual Power Electronics Specialists Conference (IEEE Cat. No. 04CH37551), Aachen, Germany, 20-25 June 2004; Volume 3, pp. 2075-2081. [CrossRef]

34. Rao, Y.; Cheng, S.; Arnold, D.P. An energy harvesting system for passively generating power from human activities. J. Micromech. Microeng. 2013, 23, 114012. [CrossRef]

35. Ylli, K.; Hoffmann, D.; Willmann, A.; Becker, P.; Folkmer, B.; Manoli, Y. Energy harvesting from human motion: Exploiting swing and shock excitations. Smart Mater. Struct. 2015, 24, 25029. [CrossRef] 
36. Wu, S.; Luk, P.C.K.; Li, C.; Zhao, X.; Jiao, Z.; Shang, Y. An electromagnetic wearable 3-DoF resonance human body motion energy harvester using ferrofluid as a lubricant. Appl. Energy 2017, 197, 364-374. [CrossRef]

37. Morais, R.; Silva, N.M.; Santos, P.M.; Frias, C.M.; Ferreira, J.A.F.; Ramos, A.M.; Simões, J.A.O.; Baptista, J.M.R.; Reis, M.C. Double permanent magnet vibration power generator for smart hip prosthesis. Sens. Actuators A Phys. 2011, 172, 259-268. [CrossRef]

38. Dai, D.; Liu, J. Hip-mounted electromagnetic generator to harvest energy from human motion. Front. Energy 2014, 8, 173-181. [CrossRef]

39. Geisler, M.; Boisseau, S.; Perez, M.; Gasnier, P.; Willemin, J.; Ait-Ali, I.; Perraud, S. Human-motion energy harvester for autonomous body area sensors. Smart Mater. Struct. 2017, 26, 35028. [CrossRef]

40. Rome, L.C. Generating Electricity While Walking with Loads. Science 2005, 309, 1725-1728. [CrossRef] [PubMed]

41. Xie, L.; Cai, M. Development of a suspended backpack for harvesting biomechanical energy. J. Mech. Des. 2015, 137, 54503. [CrossRef]

42. Hayashida, J.Y. Unobtrusive Integration of Magnetic Generator Systems into Common Footwear. Bachelor's Thesis, Department of Mechanical Engineering, MIT Media Lab, Massachusetts Institute of Technolog, Cambridge, MA, USA, 2000.

43. Purwadi, A.M.; Parasuraman, S.; Ahamed Khan, M.K.A.; Elamvazuthi, I. Development of biomechanical energy harvesting device using heel strike. Procedia Comput. Sci. 2015, 76, 270-275. [CrossRef]

44. Xie, L.; Cai, M. An in-shoe harvester with motion magnification for scavenging energy from human foot strike. IEEE/ASME Trans. Mechatron. 2015, 20, 3264-3268. [CrossRef]

45. Xie, L.; Li, J.; Cai, S.; Li, X. Design and experiments of a self-charged power bank by harvesting sustainable human motion. Adv. Mech. Eng. 2016, 8, 1-10. [CrossRef]

46. Shepertycky, M.; Li, Q. Generating electricity during walking with a lower limb-driven energy harvester: Targeting a minimum user effort. PLoS ONE 2015, 10, e0127635. [CrossRef] [PubMed]

47. Donelan, J.M.; Li, Q.; Naing, V.; Hoffer, J.A.; Weber, D.J.; Kuo, A.D. Biomechanical energy harvesting: generating electricity during walking with minimal user effort. Science 2008, 319, 807-810. [CrossRef] [PubMed]

48. Chen, C.; Yin Chau, L.; Liao, W.-H. A knee-mounted biomechanical energy harvester with enhanced efficiency and safety. Smart Mater. Struct. 2017, 26, 65027. [CrossRef]

49. Bai, P.; Zhu, G.; Lin, Z.H.; Jing, Q.; Chen, J.; Zhang, G.; Ma, J.; Wang, Z.L. Integrated multilayered triboelectric nanogenerator for harvesting biomechanical energy from human motions. ACS Nano 2013, 7, 3713-3719. [CrossRef] [PubMed]

50. Bhatia, D.; Kim, W.; Lee, S.; Kim, S.W.; Choi, D. Tandem triboelectric nanogenerators for optimally scavenging mechanical energy with broadband vibration frequencies. Nano Energy 2017, 33, 515-521. [CrossRef]

51. Li, Q.; Naing, V.; Hoffer, J.A.; Weber, D.J.; Kuo, A.D.; Donelan, J.M. Biomechanical energy harvesting: Apparatus and method. In Proceedings of the 2008 IEEE International Conference on Robotics and Automation, Pasadena, CA, USA, 19-23 May 2008; pp. 3672-3677.

52. Partridge, J.S.; Bucknall, R.W.G.; Chen, K. An analysis of the energy flow and energy potential from human energy harvesting with a focus on walking. Cogent Eng. 2016, 3, 1215203. [CrossRef]

53. Richards, C.D.; Anderson, M.J.; Bahr, D.F.; Richards, R.F. Efficiency of energy conversion for devices containing a piezoelectric component. J. Micromech. Microeng. 2004, 14, 717-721. [CrossRef]

54. Wang, G.; Luo, C.; Hofmann, H.; Rome, L. Power electronic circuitry for energy harvesting backpack. In Proceedings of the 2009 IEEE Energy Conversion Congress and Exposition, San Jose, CA, USA, 20-24 September 2009; pp. 3544-3549. [CrossRef]

55. Mitcheson, P.D.; Green, T.C.; Yeatman, E.M. Power processing circuits for electromagnetic, electrostatic and piezoelectric inertial energy scavengers. Microsyst. Technol. 2007, 13, 1629-1635. [CrossRef]

56. Szarka, G.D.; Stark, B.H.; Burrow, S.G. Review of power conditioning for kinetic energy harvesting systems. IEEE Trans. Power Electron. 2012, 27, 803-815. [CrossRef]

57. Goldfarb, M.; Jones, L.D. On the efficiency of electric power generation with piezoelectric ceramic. J. Dyn. Syst. Meas. Control 1999, 121, 566-571. [CrossRef]

58. Margaria, R. Positive and negative work performances and their efficiencies in human locomotion. Int. Z. Angew. Physiol. Einschließlich Arbeitsphysiol. 1968, 25, 339-351. [CrossRef] 
59. PowerWalk ${ }^{\circledR}$. Available online: http://www.bionic-power.com/ (accessed on 20 September 2017).

60. Wang, J.J.; Penamalli, G.P.; Zuo, L. Electromagnetic energy harvesting from train induced railway track vibrations. In Proceedings of the 2012 IEEE/ASME 8th IEEE/ASME International Conference on Mechatronic and Embedded Systems and Applications, Suzhou, China, 8-10 July 2012; Volume 11787, pp. 29-34. [CrossRef] 